\title{
Comparison between Transcerebellar Diameter, Biparietal Diameter and Femur length for Gestational Age Measurement Accuracy in Third Trimester of Pregnancy
}

\author{
Abdelmonaem Mohamed Zakaria, Ashraf Hamdy Mohamed, and Ahmed Kamal Mohamed \\ Eldarder
}

\author{
Department of Obstetrics and Gynecology, Faculty of Medicine, Al-Azhar University \\ Corresponding author: Ahmed Kamal Mohamed Eldarder, Mobile: 002001022255629, EMail: \\ ahmedeldardery2016@yahoo.com
}

\begin{abstract} diagnosis of a variety of congenital malformations. and femur length (FL). assessment of gestational age in third trimester of pregnancy. within 1 week in $123(61.5 \%)$ pregnant women.

\section{Introduction}

Gestational age (GA) refers to the length of pregnancy after the first day of the last menstrual period (LMP) and is usually expressed in weeks and days. This is also known as menstrual age ${ }^{(\mathbf{1})}$.

The 3 basic methods used to help estimate gestational age (ga) are menstrual history, clinical examination, and ultrasonography, the first 2 are subject to considerable error and should only be used when ultrasonography facilities are not available. the date of feeling the first fetal movements (quickening) is far too unreliable to be useful. The date of the first documented positive pregnancy test and the beta-human chorionic gonadotropin (BHCG) level may help ascertain the minimum gestational age. In women who conceived following assisted reproduction techniques, the date of embryo
\end{abstract}

Background: The provision of obstetric and neonatal care, as well as the public health monitoring of pregnancy outcomes, relies upon the accurate determination of gestational age. Uncertain gestational age has been associated with adverse pregnancy outcomes including low birth weight, preterm delivery and perinatal mortality, independent of maternal characteristics. The use of ultrasonography has significantly improved the evaluation of fetal growth and development and has permitted prenatal

Objective: The aim of this study was to detect an accurate method for assessment of gestational age in third trimester of pregnancy comparing the transcerebellar diameter (TCD), biparietal diameter (BPD)

Patients and Methods: A total of 200 pregnant women in third trimester pregnancy were assessed in this randomized controlled study in Department of Obstetrics and Gynecology at Sohag General Hospital by two-dimensional ultrasound from January to June 2018 to assess an accurate method for

Results: We found that out of 200 pregnant women, the TCD gave correct assessment of gestational age within 3 days in $129(64.5 \%)$ and within 1 week in $178(89 \%)$. While the FL gave correct assessment of gestational age within 3 days in 97 (48.5\%) and within 1 week in 163 (81.5\%). The least accurate was the BPD that gave correct assessment of gestational age within 3 days in $65(32.5 \%)$ and

Conclusion: It could be concluded that TCD is the most accurate method for assessment of gestational age in third trimester followed by FL, and the least accurate is the BPD.

Keywords: Transcerebellar Diameter, Biparietal Diameter, Gestational Age

transfer is known and may date the pregnancy accurately. In rare cases, the date of coitus is known, and this may be useful in calculating the length of pregnancy ${ }^{(2)}$.

Biparietal diameter considered the most broadly used for gestational age estimation. Despite that recent data established that head circumference should be used in preference to the biparietal diameter (BPD) ${ }^{(3)}$.

FL is a very useful biometric parameter used in the second and third trimesters of pregnancy. It grows linear throughout and is best measured after 14 weeks of gestation. It is measured along the long axis of the bone; a straight measurement of the osseous portion is taken from one end to the other, disregarding bone curvature ${ }^{(3)}$.

Naseem et al. ${ }^{(5)}$, did a study in 228 patients with gestational age of 36 weeks 
measuring TCD and BPD by ultrasonography. They compared GA by TCD and BPD with LMP. In this study, they observed that in 228 patients, when compared with GA by LMP, TCD had given accurate gestational age in 209 patients and BPD had given accurate gestational age in 176 patients.

The aim of this study was to detect an accurate method for assessment of gestational age in third trimester of pregnancy comparing the transcerebellar diameter, biparietal diameter and femur length.

\section{Patients and Methods}

This prospective cohort study included a total of 200 pregnant women at third trimester attending at Department of Obstetrics and Gynecology at Sohag General Hospital. Approval of the ethical committee and a written informed consent from all the subjects were obtained. This study was conducted between January to June 2o18.

Examinations were performed with the patient lying in the dorsal supine position. Two-dimensional ultrasound was carried out. Fetal biometry and amniotic fluid volume were assessed. These ultrasound parameters were measured by single sonographer to exclude bias.

\section{Inclusion criteria:}

1. Singleton uncomplicated pregnancy at third trimester.

2. Sure date of last menstrual period

3. Viable fetus in the vertex presentation.

4. History of regular menstrual cycles at least three cycles before pregnancy.

5. Gestational age in third trimester calculated from the first day of last menstrual period or by first-trimester ultrasound examination.

\section{Exclusion criteria:}

1. Patients unsure of their dates or nonreliable dates.

2. Irregular cycles.

3. Medical disorders with pregnancy as hypertension, diabetes mellitus and $\mathrm{Rh}$ iso-immunization.

4. Prelabor rupture of membranes.

5. Polyhydramnios.

6. Multiple pregnancy.

7. Congenital fetal anomalies.

8. Intrauterine fetal death.

9. Intra uterine growth retardation.
10. Antepartum hemorrhage.

11. Fetal mal-presentation.

All women included in the study were subjected to the following:

History taking:

- Gestational age of all women was confirmed by menstrual period and first trimester ultrasonography.

- Maternal medical history during pregnancy.

Clinical examination: General and abdominal examinations.

\section{Laboratory investigations:}

- Complete blood count.

- Blood grouping and Rh.

- Liver and kidney functions.

Ultrasound examination and Doppler studies for:

- Gestational age determination

- Biparietal Diameter

- Femur Length

- Trans-Cerebellar Diameter

\section{Intervention:}

Transabdominal ultrasound performed to all patients while in a slightly tilted position with the head of the bed raised 30 degrees and with a small pillow under the right loin. The apparatus which used was the Voleson 730 ProV ultrasound machine with Doppler unit and convex linear transducer 3.5 MHz. Transcerebellar diameter was measured by transverse view of fetal intracranial anatomy through the posterior fossa that included visualization of midline thalamus, cerebellar hemisphere and cisterna magna. Measurements were obtained by placing on screen calipers of ultrasound machines at the outer margins of cerebellum ${ }^{\left({ }^{(}\right)}$.

Measurement of the Biparietal diameter was taken in the lateral ventricles view, a rugby-football-shaped skull, rounded at the back (occiput) and more pointed at the front (synciput). Along midline equidistant from the proximal and distal scale echoes. The cavum septum pellucidum bisected the midline one-third of the distance from the synciput to the occiput. The two anterior horns of the lateral ventricles symmetrically placed about the midline. All or part of the posterior horns of the lateral ventricles symmetrically placed about the midline. The BPD includes the thickness of only the upper parietal bone (outer to outer measurement) ${ }^{(7)}$. 
Regarding the measurement of the femur length, the FL is imaged optimally with both ends of the ossified metaphysis clearly visible. The longest axis of the ossified diaphysis is measured. The same technique as that used to establish the reference chart should be used with regard to the angle between the femur and the insonating ultrasound beams. An angle of insonation between $45^{\circ}$ and $90^{\circ}$ is typical. Regarding the Caliper placement, each caliper is placed at the ends of the ossified diaphysis without including the distal femoral epiphysis if it is visible. This measurement should exclude triangular spur artifacts that can falsely extend the diaphysis length ${ }^{(8)}$.

The percentages of accurate assessment of gestational age by the three measurements (TCD, BPD and FL) within 3 days and within 1 week from the actual gestational age measured by LMP or first trimestric ultrasound were calculated.

\section{Statistical analysis:}

Table (1): Criteria of studied population.

\begin{tabular}{|c|c|}
\hline Variable & Summary statistics \\
\hline $\begin{array}{c}\text { Age of the mother/year } \\
\text { Mean } \pm \text { SD } \\
\text { Median }\end{array}$ & $\begin{array}{l}26.65 \pm 5.68 \\
26(17-42) \\
\end{array}$ \\
\hline $\begin{array}{c}\text { Body mass index }\left(\mathbf{k g} / \mathbf{m}^{2}\right) \\
\text { Mean } \pm \text { SD } \\
\text { Median }\end{array}$ & $\begin{array}{l}27.34 \pm 3.89 \\
28.5(22-35)\end{array}$ \\
\hline $\begin{array}{c}\text { Number of previous deliveries } \\
0 \\
1 \\
2 \\
3 \\
4 \\
5 \\
6 \\
7\end{array}$ & $\begin{array}{c}61(30.50 \%) \\
30(15.00 \%) \\
49(24.50 \%) \\
31(15.50 \%) \\
13(6.50 \%) \\
8(4.00 \%) \\
7(3.50 \%) \\
1(0.50 \%)\end{array}$ \\
\hline $\begin{array}{c}\text { Number of previous abortions } \\
0 \\
1 \\
2 \\
3 \\
4 \\
\end{array}$ & $\begin{array}{c}136(68.00 \%) \\
33(16.50 \%) \\
22(11.00 \%) \\
8(4.00 \%) \\
1(0.50 \%) \\
\end{array}$ \\
\hline $\begin{array}{c}\text { Use of contraceptive } \\
\text { No } \\
\end{array}$ & $200(100 \%)$ \\
\hline $\begin{array}{c}\text { Regularity of cycle } \\
\text { Regular }\end{array}$ & $200(100 \%)$ \\
\hline $\begin{array}{c}\text { Gestational age /days } \\
\text { Mean } \pm \text { SD } \\
\text { Median } \\
\end{array}$ & $\begin{array}{l}244.84 \pm 19.72 \\
248(206-278)\end{array}$ \\
\hline $\begin{array}{c}\text { Gestational age /week } \\
\text { Mean } \pm \text { SD } \\
\text { Median }\end{array}$ & $\begin{array}{c}34.98 \pm 2.82 \\
35.43(29.43-39.71)\end{array}$ \\
\hline
\end{tabular}

Our patients showed that the percentages of accurate assessment of gestational age within 3 days were as follow: Out of 200 patients, TCD gave accurate assessment within 3 days in 129 patients (64.5\%), FL gave accurate assessment within 3 days in 97 patients (48.5\%), while the BPD gave accurate assessment within 3 days in 65 patients (32.5\%). 
Comparison between Transcerebellar Diameter, Biparietal Diameter...

On comparison between accuracy of BPD and TCD within three days The p value was found to be < 0.0001 showing that there is highly significant difference between correct assessment within 3 days by BPD and by TCD.

Table (2): Comparison between TCD and BPD within 3 days

\begin{tabular}{|c|c|c|c|c|c|c|}
\hline & \multicolumn{2}{|c|}{ BPD } & \multicolumn{2}{|c|}{ TCD } & \multirow{2}{*}{$P$ value } \\
\hline & & Count & $\%$ & Count & $\%$ & \\
\hline \multirow{2}{*}{ Accuracy } & yes & 65 & 32.50 & 129 & 64.50 & \multirow{2}{*}{$<0.0001$} \\
\hline & no & 135 & 67.50 & 71 & 35.50 & \\
\hline
\end{tabular}

On comparison between accuracy of FL and TCD within three days the p value was found to be < 0.0001 showing that there is highly significant difference between correct assessment within 3 days by FL and by TCD.

Table (3): Comparison between TCD and FL within 3 days

\begin{tabular}{|l|l|c|c|c|c|c|}
\hline \multicolumn{2}{|c|}{} & \multicolumn{2}{|c|}{ TCD } & \multicolumn{2}{c|}{ FL } & \multirow{2}{*}{ P value } \\
\cline { 3 - 6 } \multicolumn{2}{|c|}{} & Count & \% & Count & \% & \multirow{2}{*}{$\mathbf{0 . 0 0 0 1}$} \\
\hline \multirow{2}{*}{ Accuracy } & yes & 129 & 64.50 & 97 & 48.50 & 51.50 \\
\cline { 2 - 6 } & no & 71 & 35.50 & 103 & \\
\hline
\end{tabular}

On comparison between accuracy of BPD and FL within three days the p value was found to be < o.0oo1 showing that there is highly significant difference between correct assessment within 3 days by BPD and by FL.

Table (4): Comparison between BPD and FL within 3 days

\begin{tabular}{|c|c|c|c|c|c|c|}
\hline & \multicolumn{2}{|c|}{ BPD } & \multicolumn{2}{|c|}{ FL } & \multirow{2}{*}{$P$ value } \\
\hline & & Count & $\%$ & Count & $\%$ & \\
\hline \multirow{2}{*}{ Accuracy } & yes & 65 & 32.50 & 97 & 48.50 & \multirow{2}{*}{0.0001} \\
\hline & no & 135 & 67.50 & 103 & 51.50 & \\
\hline
\end{tabular}

On comparison between accuracy of BPD and TCD within one week, the p value was found to be < 0.0001 showing that there is highly significant difference between correct assessment within 7 days by BPD and by TCD.

Table (5): Comparison between TCD and BPD within one week

\begin{tabular}{|c|c|c|c|c|c|c|}
\hline & \multicolumn{2}{|c|}{ BPD } & \multicolumn{2}{|c|}{ TCD } & \multirow{2}{*}{$P$ value } \\
\hline & & Count & $\%$ & Count & $\%$ & \\
\hline \multirow{2}{*}{ Accuracy } & yes & 123 & $61.5 \mathrm{o}$ & 178 & 89.00 & \multirow{2}{*}{$<0.0001$} \\
\hline & no & 77 & 38.50 & 22 & 11.00 & \\
\hline
\end{tabular}

On comparison between accuracy of FL and TCD within one week, the p value was found to be < 0.003 showing that there is no significant difference between correct assessment within one week by FL and by TCD.

Table (6): Comparison between TCD and FL within one week

\begin{tabular}{|l|l|c|c|c|c|c|}
\hline \multicolumn{2}{|c|}{} & \multicolumn{2}{|c|}{ TCD } & \multicolumn{2}{c|}{ FL } & \multirow{2}{*}{ P value } \\
\cline { 3 - 6 } \multicolumn{2}{|c|}{ Accuracy } & Count & \% & Count & \% & \multirow{2}{*}{$\mathbf{0 . 0 3}$} \\
\cline { 2 - 6 } & yes & 178 & 89.00 & 163 & 81.50 & 18.50 \\
\hline
\end{tabular}

On comparison between accuracy of BPD and FL within one week, the p value was found to be < 0.0001 showing that there is highly significant difference between correct assessment within one week by BPD and by FL. 


\section{Abdelmonaem Zakaria et al.}

Table (7): Comparison between BPD and FL within one week.

\begin{tabular}{|c|c|c|c|c|c|c|}
\hline & \multicolumn{2}{|c|}{ BPD } & \multicolumn{2}{|c|}{ FL } & \multirow{2}{*}{$P$ value } \\
\hline & & Count & $\%$ & Count & $\%$ & \\
\hline \multirow{2}{*}{ Accuracy } & yes & 123 & 61.50 & 163 & 81.50 & \multirow{2}{*}{$<0.0001$} \\
\hline & no & 77 & 38.50 & 37 & 18.50 & \\
\hline
\end{tabular}

\section{Discussion}

The determination of gestational age is important in obstetrics for management of pregnancy and evaluation of fetal development.

In the current study we found that out of 200 patients, the TCD gave correct assessment of gestational age within 3 days in 129 patients $(64.5 \%)$ and within 1 week in 178 patients (89\%). While the FL gave correct assessment of gestational age within 3 days in 97 patients (48.5\%) and within 1 week in 163 patients $(81.5 \%)$. The least accurate was the BPD that gave correct assessment of gestational age within 3 days in 65 patients $(32.5 \%)$ and within 1 week in 123 patients $(61.5 \%)$

In the current study, we detected an accurate method for assessment of gestational age in third trimester of pregnancy comparing the transcerebellar diameter, biparietal diameter and femur length. This study is important especially in our country as many of our patients attend the hospitals without medical record or previous antenatal care visits especially in low socioeconomic standards, not remembering their LMP or their EDD which in return makes it very difficult on the physician to assess the gestational age of the fetus. Uncertain gestational age has been associated with adverse pregnancy outcomes including low birth weight, preterm delivery and perinatal mortality, post term pregnancy and macrosomia.

Prssad and Likhitha ${ }^{(9)}$ studied an equation that correlates between the GA and the TCD and detected a good correlation between the GA and TCD throughout the third trimester and even in the case of intra uterine growth retardation (IUGR).

In another study done by Naseem $\boldsymbol{e t}$ al. ${ }^{(5)}$ on 327 patients pregnant in their third trimester comparing TCD with FL showed that TCD is more reliable method of gestational age determination in third trimester than FL.

Akl et al. ${ }^{(6)}$ performed a study in Egypt on 150 pregnant women in their third trimester to determine the accuracy of the TCD in assessment of gestational age and he concluded that the TCD is a reliable method for assessment of gestational age in third trimester of pregnancy.

Reddy et al. ${ }^{(10)}$ evaluated accuracy of predicting GA using Fetal Transcerebellar Diameter (TCD) and to compare between TCD and other existing parameters in evaluating GA in 15 to 40 weeks of gestation. They showed that TCD is an accurate parameter in estimation of gestational age in second and third trimesters as its values are in close relation with that of GA by LMP. It is also better predictor of the gestational age when compared to other parameters especially in third trimester.

Limitation of this study include small sample size (200 cases), and to determine accuracy of transcerebellar diameter in estimating gestational age by using last menstrual period as gold standard, we excluded many cases with irregular cycles or unsure of date of last menstrual period which decrease our sample size. Also this study included only singleton healthy pregnancy with exclusion of any malformed, multiple pregnancy, intrauterine growth restriction or macrosomic babies. Hence further studies with larger sample size including growh restricted and macrosomic fetuses may be required to support our finding and to establish transcerebellar diameter as an accurate and more reliable parameter in estimation of gestation age in third trimester.

\section{Conclusion}

From the ongoing study, we can conclude that TCD is the most accurate method for assessment of gestational age in third trimester followed by FL, and the least accurate is the BPD. Also, by combining accuracy of TCD (89\%) and that of FL (81\%), we can be near certain of gestational age in most of our patients even if they are unsure of their dates.

\section{Recommendations}

1. Measuring the TCD as routine in the third trimester as it has the same 
accuracy as the current fetal biometry (BPD and FL).

2. Further study assessing the accuracy of the TCD in estimation of the gestational age in extremes of fetal growth; IUGR and fetal macrosomia.

3. We recommend conducting this study on larger sample size for further documentation of the proposed assumption.

\section{References}

1. Lohr PA, Reeves MF and Creinin MD (2010): A comparison of transabdominal and transvaginal ultrasonography for determination of gestational age and clinical outcomes in women undergoing early medical abortion. Contraception, 81(3):240244.

2. Wu FS, Hwu YM, Lee RK et al. (2012): First trimester ultrasound estimation of gestational age in pregnancies conceived after in vitro fertilization. Eur. J. Obstet. Gynecol. Reprod. Biol., 160(2):151-5.

3. Chudleigh $\mathbf{T}$ and Thilaganathan $\mathbf{B}$ (2005): Obstetric ultrasound: How, why, and when, 2005. https://www.amazon.com/ObstetricUltrasound-How-Why-When/dp/ 0443054711

4. Butt $K$ and Lim $K$ (2014): Determination of gestational age by ultrasound. J. Obstet. Gynaecol. Can., 36(2): 171-181.
5. Naseem F, Ali $\mathrm{S}$, Basit $\mathrm{U}$ et al. (2014): Assessment of gestational age: Comparison between transcerebellar diameter versus femur length on ultrasound in third trimester of pregnancy. Professional Med. J., 21(2): 412-417.

6. Akl S, Mohammed M, Bahaa El-din A et al. (2014): Accuracy of Transcerebellar Diameter at the Third Trimester in Estimating the Gestational Age in Singleton Pregnancy. Med. J. Cairo Univ., 82(1): 879-884.

7. Hadlock FP, Deter RL, Harrist RB et al. (1983): Fetal biparietal diameter: Rational choice of plane of section for sonographic measurement. AJR., 138: 871.

8. Salomon L, Alfirevic Z, Berghella V et al. (2011): Practice guidelines for performance of the routine midtrimester fetal ultrasound scan. Ultrasound in Obstetrics \& Gynecology, 37: 116-126.

9. Prssad BS and Likhitha S (2014): Cerebellar measurements with ultrasonography in evaluation of fetal age. IOSR Journal of Dental and Medical Sciences, 13(9): 49-56.

10. Reddy RH, Prashanth $K$ and Ajit $M$ (2017): Significance of foetal transcerebellar diameter in foetal biometry: A pilot study. Journal of Clinical and Diagnostic Research, 11(6): 01-04. 